$$
\xi
$$




\section{Comparación entre el incompatibilismo de Skinner y el compatibilismo de Dennett: libertad y determinismo}

\section{Introducción}

Siempre ha existido un contante problema entre la libertad y el determinismo, como si se negaran una idea a la otra, pero ¿por qué el determinismo es tan cerrado con la idea de la libertad?, ¿qué pasaría si el determinismo no fuera tan duro y admitiera a la libertad como parte del ser humano?, ¿cuál postura es más convincente en su forma de ver la libertad?

En este trabajo analizaré el determinismo y su relación con la libertad, para poder resolver las preguntas anteriores, abordando dos posturas diferentes: el incompatibilismo de Skinner y el compatibilismo de Dennett; revisaré los argumentos que ofrece cada autor en torno a la existencia o inexistencia de la libertad; después analizaré estos argumentos un poco más a fondo, y al final daré mi opinión sobre cuál postura ofrece una mejor opción acerca de la existencia de la libertad o si ésta sólo es un sentimiento y todo en este mundo está determinado.

\section{Postura incompatibilista de Skinner}

El incompatibilismo es una postura en la que el determinismo y la libertad nunca serán compatibles. Dentro de ésta existen varias posturas. Por una parte, los libertaristas creen en el libre albedrío y no creen que el determinismo sea una ley universal. Por otra y para lo que vamos a analizar a continuación, tenemos a los deterministas duros, quienes piensan que el libre albedrío no existe porque el determinismo es cierto.

Burrhus Frederic Skinner es un determinista duro, quien no cree que exista la libertad por los siguientes motivos: 
1. Se opone a la idea de libre albedrío que concibe a la conducta como actos caprichosos de un agente libre y no determinado causalmente. La idea de que el individuo está más allá de factores controladores conduce a ignorar esos factores. Las formas más peligrosas de control son las menos evidentes, que permiten que el individuo se sienta libre.

2. Los discursos sobre la libertad estarían motivados por cualquiera de esas dos reacciones de rechazo hasta el punto de que, según Skinner, el pensamiento sobre la libertad está hecho para estimular a la gente a la acción, pero no imparte ningún conocimiento sobre la libertad. Estaríamos ante una incitación a la liberación, pero no ante una verdadera filosofía de la libertad.

3. Si la filosofía de la libertad ha sido importante es porque, según Skinner, la gente se somete con demasiada facilidad a los estados de dominación, por lo que estas incitaciones de liberación sirven de contrapunto o formas de suavizar el control.

4. El conductismo de Skinner considera la libertad como una función de las situaciones de refuerzo ambientales.

5. Esta postura fue con frecuencia malinterpretada como si afirmara que el sujeto es pasivo, o propusiera el fatalismo ("estamos determinados y no podemos cambiar"), o negara la dimensión ética ("si estamos determinados no somos responsables de nuestros actos"). En realidad no propone que el sujeto sea pasivo (la conducta operante es precisamente activa e intencional), ni el fatalismo (el aprendizaje es precisamente cambiar), ni niega la ética (que involucra las contingencias de la comunidad moral). ${ }^{1}$

\section{Postura compatibilista de Dennett}

El compatibilismo es una postura donde el libre albedrío no está peleado con el determinismo; claro que los deterministas que se

1 A. Antolin, Jean Pierre Massola y María Teresa Rojano, Skinner y su concepto del hombre y la sociedad (no es exactamente igual pero de ahí tomé la idea). 
encuentran en esta postura tienen que hacer unas cuantas modificaciones al determinismo para poder aceptar el libre albedrío, pero siguen creyendo en la determinación.

Daniel Clement Dennett es un compatibilista, quien cree que existe un libre albedrío compatible con el determinismo. A continuación sus puntos de vista:

1. Su propuesta sobre la libertad se encuadra en un planteamiento naturalista, según el cual las investigaciones filosóficas no son superiores ni previas a las investigaciones de las ciencias naturales, sino que van asociadas a dichos proyectos, y el auténtico trabajo que deben hacer los filósofos en esta cuestión es clarificar y unificar las muchas perspectivas contrapuestas en una visión unificada del universo.

2. La concepción concreta de Dennett es que acepta el determinismo, pero al mismo tiempo se niegan algunos de los rasgos que tradicionalmente se han asociado a él, como la inevitabilidad, o se defienden otros que se creían incompatibles con el mismo, como el control, el actuar por razones, el tener un futuro abierto y la responsabilidad. En su libro La evolución de la libertad, Dennett va a utilizar un modelo para mostrar cómo podría darse el determinismo y a la vez negar esas características propias de él como la inevitabilidad.

3. La propuesta de Dennett, por tanto, es que mientras el determinismo se produciría en el nivel físico, la evitabilidad nos la encontramos cuando nos situamos en el nivel del diseño, esto es, en el nivel de los dioses-hackers. La función que cumplen en ese nivel del diseño los dioses-hackers en el mundo Vida, en nuestro mundo real, la realizaría la evolución, que es quien nos ha ido diseñando a lo largo del tiempo. En consecuencia, para Dennett, determinismo y libertad son compatibles porque al hablar de uno y de otra adoptamos distintas perspectivas y nos situamos en niveles diferentes de descripción.

4. El argumento que va a dar Dennett para mostrar que el determinismo no quita posibilidades toma como 
punto de partida la tesis de que, cuando sostenemos que podríamos haber obrado de otro modo, lo que queremos decir no es que en exactamente las mismas circunstancias podríamos haber hecho otra cosa diferente de la que hicimos, sino que en circunstancias muy parecidas, aunque levemente diferentes, podríamos haber hecho otra cosa.

5. Además, Dennett cree que la cuestión metafísica de si podríamos haber obrado de otro modo no tiene respuesta y si la tuviera no sería de ninguna utilidad, puesto que ya no se puede cambiar lo que hayamos hecho. Por tanto, propone que el sentido de posibilidad que es importante para el libre albedrío es el epistémico. Las posibilidades dependen del conocimiento limitado de los seres de que se trate, esto es, la libertad es posible siempre que "cada usuario finito de información tiene un horizonte epistémico; no sabe todo del mundo que habita, y esta ignorancia insuperable garantiza que tenga un futuro subjetivamente abierto".

\section{¿Qué es la libertad para Skinner y para Dennet?}

Skinner realmente no define la libertad porque para él tal cosa no existe, igual que cualquier entidad mental; es decir, no hay emociones, sentimientos, deseos, sensaciones, etcétera. Rechaza esas entidades porque no tienen importancia en el comportamiento del ser humano, por lo cual, para él, los seres humanos ni pensamos, ni sentimos. Aquéllas son palabras que para Skinner no tienen significado, ya que el comportamiento depende del medio ambiente.

La concepción del ser humano para Skinner sobre la naturaleza del hombre es de un conjunto de propiedades características y exclusivas del ser humano, pero tales características no existen. El ser humano es mero comportamiento y como tal depende del medio ambiente: si el medio ambiente cambia, el comportamien-

2 Guerrero del Amo, José Antonio, Las dificultades del compatibilismo de Dennett, Universidad Complutense de Madrid (comprende desde el punto 1 al punto 5). 
to cambia, la personalidad cambia. El ser humano no es más que mera conducta. El hombre ni es libre, ni tiene dignidad sólo por el hecho de ser hombre; somos lo que el medio ambiente nos hace.

En cuanto a Dennett, éste es uno de los pocos intelectuales serios que quiere desarrollar toda una teoría de la libertad. Para él, la libertad no es más que la ausencia de coacción. Un perro "elige libremente" entre dos montones de comida después de haberlos olisqueado. Exactamente lo mismo que yo "elijo libremente" si voy a gastarme cien pesos en unas entradas para un espectáculo o voy a destinar esa cantidad a una causa benéfica. En ninguno de estos casos existe coacción. Y, con respecto a la responsabilidad moral, Dennett diría que somos responsables de lo que hacemos en la medida en que somos conscientes de nuestros propios deseos y de que actuamos según ellos. Para aquél, la responsabilidad moral no tiene nada que ver con el mecanismo causal (biológico) que supuestamente determina todos nuestros deseos y todas nuestras acciones. Dennett, de algún modo, ve al hombre en su evolución como un ser que cada vez es más complejo y, por lo tanto, más libre. ${ }^{3}$

\section{Revisión de sus argumentos}

\section{El tópico en común en la discusión}

A lo largo de este trabajo encontramos algo en común entre los dos autores y es que ambos creen en conductas aprendidas. Claro que Skinner ve a las conductas como condicionamiento del comportamiento de los seres humanos, por eso mismo éstos no tienen capacidad de elegir nada que no sea lo aprendido, y Dennett, además de creer en esto, agrega que a pesar de que tenemos conductas determinadas, los resultados pueden variar dependiendo de nuestra capacidad para evaluar las alternativas de decisión.

Con lo anteriormente dicho, notamos que Skinner es regularista humeano y Dennett es regularista nómico.

Skinner es humeano pero sólo en parte, porque:

3 Arana, Juan, Los filósofos y la libertad, Editorial Síntesis, 2005, Madrid, pp. 238-250. (Basé toda esta idea en el texto del libro sólo que lo resumí.) 
1. Propone un tipo de causalidad distinto de la causalidad humeana (tipo bola de billar, la causa/antecedente compele al efecto). Esta forma de causalidad es semejante a la selección natural: así como las variaciones genéticas son seleccionadas o descartadas por sus consecuencias, las nuevas formas de conducta son seleccionadas o descartadas por el reforzamiento. Cuando ocurre una conducta le siguen ciertas consecuencias ambientales cuyos efectos (cambios en la conducta) usualmente se detectarán más tarde. La conducta es función de sus consecuencias ambientales pasadas.

2. Se diferencia de los modelos conductistas de estímulo-respuesta y las teorías mentalistas deterministas, que toman sólo el modo causal humeano. Conserva la idea de causalidad humeana para la conducta respondiente, y agrega la idea de causalidad consecuencial en la conducta operante.

3. Los genes no determinan directamente la conducta, la relación es más compleja. Toda conducta es condicionada por factores genéticos y ambientales.

Dennett es regularista nómico por lo siguiente:

1. Para explicar esto vamos a recurrir a la metáfora donde podemos contrastar nuestras intuiciones tomando como referencia al mundo Vida de Conway, donde sí conocemos perfectamente las leyes físicas y sabemos que se trata de un mundo determinista.

2. Ahora, a pesar de que es un mundo determinista tenemos posibilidades; éstas se generan, según Dennett, dependiendo de qué tanto conocimiento tenemos de nuestro entorno, de las posibilidades de otros mundos y también de la evolución de los seres humanos, organismos vivientes que tienen la capacidad de aprender conductas y evaluar alternativas de decisión.

3. Para Dennett, aunque está determinado que algo suceda no significa que esa era la única opción o que en cualquier mundo posible eso era lo único que podía pasar, sino que también hay otras posibilidades. 
Aspectos principales que debe de tener toda teoría en sus argumentos

En ambos casos el contenido es públicamente observable, puesto que sus ideas están plasmadas en libros que se pueden comprar y hay muchos comentadores de ellos para consultar. Los libros a los que me refiero serían principalmente, de Skinner, Mas allá de la libertad y la dignidad, y en el caso de Dennett, La evolución de la libertad. Si hablamos de que sea públicamente corregible, en lo personal y por lo que he leído, ellos mismos se la pasaron corrigiendo su trabajo, y aunque fuera un golpe a su orgullo, también han dejado que los corrigieran; aunque Skinner ya falleció, Dennett hoy en día aún sigue siendo corregido por muchos de sus detractores, pero esto, lejos de desanimarlo, lo ayuda a fortalecer sus argumentos. Para terminar con este aspecto de su argumentación tenemos el compromiso fisicalista de cada uno. Tanto Skinner como Dennett, cada uno a su modo, proponen casos concretos que no necesitan de suposiciones absurdas de entes que manipulen al hombre o le den algún tipo de conocimiento divino, que lo ayuden a tener libre albedrío (Dennett) o que lo tengan como simple siervo (Skinner).

\section{Contenido especifico de cada propuesta}

Una vez revisadas las bases de los argumentos podemos exponer el contenido más específico de cada cara de la moneda; esto se hará en la siguiente tabla.

\begin{tabular}{|c|c|c|}
\hline Contenido & Skinner & Dennett \\
\hline $\begin{array}{l}\text { Sentido } \\
\text { (explicativo y } \\
\text { significativo) }\end{array}$ & $\begin{array}{l}\text { La forma que tiene para } \\
\text { explicar su postura me } \\
\text { gusta mucho, porque puedo } \\
\text { entenderla. Sé que intenta } \\
\text { explicar por qué no existe } \\
\text { la libertad. En cuanto a él, } \\
\text { por qué es importante que } \\
\text { no exista la libertad no me } \\
\text { queda muy claro. }\end{array}$ & $\begin{array}{l}\text { Su forma de explicar por qué } \\
\text { la libertad existe es interesante, } \\
\text { pero debo confesar que tuve } \\
\text { que leer más sobre él para } \\
\text { entenderlo. En cuanto a para } \\
\text { qué explica que la libertad } \\
\text { existe, me queda muy claro } \\
\text { que es porque en cierto } \\
\text { punto de la determinación } \\
\text { de las cosas necesita del libre } \\
\text { albedrío, según él. }\end{array}$ \\
\hline
\end{tabular}




\begin{tabular}{|c|c|c|}
\hline Relevancia & $\begin{array}{l}\text { Skinner, para fundamentar } \\
\text { que no existe la libertad, } \\
\text { habla de conductismo en el } \\
\text { hombre y si lo comparamos } \\
\text { con la postura de Dennett } \\
\text { resulta menos relevante. }\end{array}$ & $\begin{array}{l}\text { Dennett, en cambio, habla } \\
\text { sobre la evolución en el } \\
\text { hombre y que ésta siempre } \\
\text { va a alterar la conducta de los } \\
\text { hombres. }\end{array}$ \\
\hline Claridad & $\begin{array}{l}\text { La claridad de Skinner es } \\
\text { extrañamente muy buena y } \\
\text { sus ejemplos son buenos. }\end{array}$ & $\begin{array}{l}\text { Dennett es un poco más } \\
\text { difícil. No es muy claro a } \\
\text { veces y se debe consultar a sus } \\
\text { comentaristas; sus ejemplos sí } \\
\text { son buenos. }\end{array}$ \\
\hline Concisión & $\begin{array}{l}\text { No puedo negar que este } \\
\text { hombre sabe ir al punto sin } \\
\text { dar muchas vueltas. }\end{array}$ & $\begin{array}{l}\text { Intenta ser conciso pero a } \\
\text { veces el que sea tan conciso } \\
\text { no le ayuda. Un poco más } \\
\text { de explicación no le vendría } \\
\text { mal y ayudaría a su mejor } \\
\text { comprensión. }\end{array}$ \\
\hline
\end{tabular}

\section{Conclusión}

Al final de todo sólo puedo concluir que la libertad es una condición evolutivamente fundada y presente en una enorme cantidad de organismos vivientes que tienen la capacidad de aprender conductas y evaluar alternativas de decisión. Sin embargo, en el caso específico del ser humano, y como producto de su propia evolución, esta capacidad se halla significativamente más desarrollada que en el resto de los seres vivientes, así que por el momento la postura más aceptable sería la actitud compatibilista de Dennett, puesto que define la libertad e incluso la hace parte importante en el determinismo del ser humano. No obstante, esta postura me parece extraña porque no creo que la libertad sea algo biológico. Entiendo que tiene mucho más potencial, que es algo todavía más complicado y que necesita más atención y estudio de nuestra parte. 
